\title{
Spondyloarthritis with Psoriasis: New Insights
}

\section{Yasser El Miedany*}

Darent Valley Hospital, Dart ford, Kent, DA2 8DA, England

\begin{abstract}
There is a growing interest in psoriasis and psoriatic arthritis which moved from rather restricted and longstanding disease approach to a more comprehensive view, encompassing not only inflammatory back pain, but also peripheral arthritis, enthesitis, as well as co morbidities and extra-articular manifestations. The fact that psoriasis precedes joint disease in most patients provides an opportunity to identify those patients most likely to develop arthritis. The introduction of the "window of opportunity" concept into psoriatic arthritis management and the potential role of "early psoriatic arthritis" service to identify those suffering from active inflammatory disease have led to a significant change in the way these patients are managed. The recognition of a non-radiographic stage in early spondyloarthritis opened the door for imaging modalities such as MRI and US to book its place in the diagnosis of the pre-radiographic changes. This article will focus on recent developments in PsA pathogenesis, diagnostic strategies to identify patients with early psoriatic musculoskeletal inflammation in standard clinical practice and the implementation of patient reported outcome measures as well as imaging modalities for the diagnosis and management of the disease.
\end{abstract}

Keywords: Psoriatic arthritis; Spondyloarthritis; MRI; Ultrasonography (US); Early psoriatic arthritis; Patient reported outcome measures (PROM); Patient education

\section{Introduction}

Although initially considered a variant of rheumatoid arthritis, psoriatic arthritis (PsA) emerged as a distinct clinical entity of inflammatory arthritis associated with psoriasis $[1,2]$. In contrast with rheumatoid arthritis, PsA is notable for its diversity in presentation, expression and clinical course. Disease presentation can vary from subtle enthesitis pain to arthritis mutilans, a highly destructive form of arthritis. The expression of clinical features is also quite variable and can involve a wide array of tissues, including synovium, cartilage, bone, entheses and tendons, in addition to skin and nails. Unlike rheumatoid arthritis, the prevalence of the disease is equal in women and men, with an incidence of approximately 6 per 100,000 per year, and a prevalence of about 1 to 2 per $1000[1,3-8]$.

With the characteristic inflammatory manifestations of both spinal and peripheral joints, PsA is now recognized as one of the spondyloarthritis (SpA) family. Not surprisingly, the clinical course of PsA is unpredictable, although evidence indicates that it can be a debilitating condition that leads to increased morbidity and mortality [3]. Radiographic damage can occur within 2 years of disease onset in almost half of patients with PsA, and the disease follows a chronic, progressive course in most patients $[9,10]$. The recognition that PsA can lead to marked joint destruction with consequent impairment of the patients' quality of life has modified the treatment paradigm. Increased emphasis is now placed on disease remission and prevention of joint damage, in addition to reducing pain, improving function, ability to work as well as quality of life. These goals can best be achieved by early diagnosis and intervention $[11,12]$.

This article will focus on the recent developments in PsA pathogenesis, diagnostic strategies to identify patients with early psoriatic musculoskeletal affection and the implementation of patient reported outcome measures as well as imaging modalities for the diagnosis and management of the disease.

\section{Finding a common language for spondyloarthritis}

The terms spondyloarthritis, spondyloarthritides, spondyloarthropa- thy, and spondyloarthropathies are used to refer to a family of diseases that share several clinical features (Figure 1). The most distinguishing features are inflammation of axial joints (especially the sacroiliac joints), asymmetric arthritis (whether oligo- or polyarticular), dactylitis (diffuse swelling of a digit may be acute, with painful inflammatory changes, or chronic; where the digit remains swollen despite the disappearance of acute inflammatory changes), and enthesitis (inflammation at sites of ligamentous or tendon attachment to bones). Additional features are genital (balanitis, urethritis/cervicitis), skin lesions, nail dystrophy, eye and bowel inflammation, an association with preceding or ongoing infectious disorders, and a strong association with the human leukocyte antigen (HLA) B27. Psoriatic arthritis covers a wide spectrum of disease manifestations, including peripheral and axial arthritis. The new classification criteria for both axial and peripheral spondyloarthritis constitute one of the most important advances in the last few years. Spondyloarthritis ( $\mathrm{SpA})$ has been agreed as the preferred

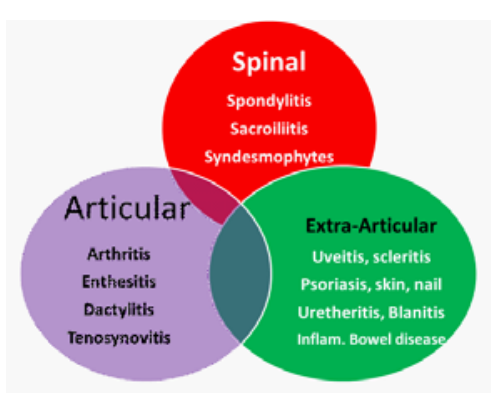

Figure 1: Clinical manifestation of the Spondyloarthritides, which may be present in the different disease entities.

*Corresponding author: Yasser El Miedany, Consultant Rheumatologist, Darent Valley Hospital, Dart ford, Kent, DA2 8DA, England,E-mail: yasser_elmiedany@yahoo.com

Received July 17, 2012; Accepted October 25, 2012; Published October 29, 2012

Citation: Miedany YEI (2012) Spondyloarthritis with Psoriasis: New Insights. J Arthritis 1:106. doi:10.4172/2167-7921.1000106

Copyright: (c) 2012 Miedany YEl, et al. This is an open-access article distributed under the terms of the Creative Commons Attribution License, which permits unrestricted use, distribution, and reproduction in any medium, provided the original author and source are credited. 


\begin{tabular}{|l|l|}
\hline Old & New \\
\hline Ankylosing Spondylitis & Axial radiographic Spondyloarthritis \\
\hline Undifferentiated spondyloarthritis & $\begin{array}{l}\text { Axial non-radiographic } \\
\text { Spondyloarthritis }\end{array}$ \\
\hline Psoriatic Arthritis & Spondyloarthritis with Psoriasis \\
\hline Reactive Arthritis & $\begin{array}{l}\text { Peripheral Spondyloarthritis with } \\
\text { infection preceding arthritis }\end{array}$ \\
\hline $\begin{array}{l}\text { Spondyloarthritis associated with Crohn's } \\
\text { disease and ulcerative colitis }\end{array}$ & $\begin{array}{l}\text { Spondyloarthritis with inflammatory } \\
\text { bowel disease }\end{array}$ \\
\hline
\end{tabular}

Table 1: The new proposed titles for the different rheumatic conditions causing axial spondylitis as well as peripheral inflammatory arthritis with Spondyloarthritis as the common denominator.

term for this family. Furthermore, ASAS recognized that the term spondyloarthritis is preceded by both the main clinical presentation of the disease (e.g. axial versus peripheral) and radiological presentation (the presence or not of radiological structural damage). The current proposal is to use the term "radiographic" in case of demonstration of axial presentation such as sacroiliac structural changes (e.g. subchondral bone osteosclerosis, joint erosions or fusion) and the term of "erosive" in case of peripheral presentation).

Therefore, axial radiographic spondyloarthritis should replace "ankylosing spondylitis" [13]. Table 1 shows the new titles proposed for the different rheumatic conditions included under the term spondyloarthritis.

\section{Pathogenesis}

The skin and joints of patients suffering from spondyloarthritis with psoriasis show significant similarities, including the histological structure as well as the nature of the inflammatory infiltrate. The efficacy of immune modulating therapies in the treatment of both psoriasis and PsA implicates shared immunologic mechanisms in the pathogenesis of both manifestations. Both skin and synovium are characterized by marked vascularity and robust mononuclear inflammatory infiltration that includes dendritic cells (DC), activated $\mathrm{T}$ cells and tissue macrophages [14]; in addition to multiple genetic risk factors encoded by these immune cells which are recently beginning to be identified [15].

The enthesis organ: The concepts of the "enthesis organ" and the "synovio-entheseal complex" were recently introduced as possible mechanism of inflammation that demarcates PsA from other forms of inflammatory arthritis such as rheumatoid arthritis. The historical perception in PsA and psoriasis was that auto reactive lymphocytes targeted a common unidentified auto antigen in the skin and synovial membrane. However, it is now evident from imaging studies that enthesitis is the key pathological lesion in PsA and that entheses form functionally integrated units with adjacent synovium in structures termed synovio-entheseal complexes [16]. These structures appear to be associated with micro damage at insertion sites in normal joints leading to microscopic synovitis in adjacent soft tissues. Therefore, the common denominator in PsA may be related to aberrant responses to stress at the enthesis. This offers a new biomechanical model for joint disease in PsA. This "non-immunological" or tissue specific factors could be a key to the expression of the disease at different musculoskeletal sites [17].

The biochemical model as a possible mechanism of inflammation was further supported by the findings of McGonagle et al. study [18] which revealed similarities between the epidermis and dermis of the skin on one hand and the junction where a fibro cartilaginous tendon or ligament is inserted onto a bone on the other hand. In both cases an avascular tissue (epidermis, fibrocartilage) is attached to a vascular tissue (dermis, bone) at an irregular interface that protects against shear. Furthermore, the fibrocartilage at the enthesis has a tidemark that separates two tissues of different physical properties (calcified fibrocartilage and uncalcified fibrocartilage) similar to the epidermis which has a stratum granulosum at the interface between the mechanically significant cornified layer and the deeper, living epidermal cells. The distribution of blood vessels is confined to the dermis in the skin (where there is a rich capillary bed in the papillary layer immediately beneath the epidermis) and the bone at the enthesis. Of particular note is that either dermal inflammation (in the case of the skin) or osteitis (in the case of psoriatic arthritis) is well recognized in patients with psoriasis or PsA.

The interaction of adaptive and innate immunity: Pathological studies in psoriatic patients revealed a prominent, lymphocytic infiltrate in the inflamed tissues, both in the skin localized to the dermal papillae, and in the joint at the sub lining layer stroma. There is evidence of a possible role for both the adaptive immune system (viral or streptococcal infections leading to CD4+/CD8+ T cell activation) and the innate immune system (activated macrophages, keratinocytes/dendritic antigen presenting cells, natural killer (NK), and NKT cells) [19]. T lymphocytes expressing CD4 are the most abundant inflammatory cells in the tissues, with a 2:1 ratio of CD4 to CD8+ T cells. B lymphocytes were also found in the skin and joints, occasionally forming primitive germinal centers. It has been suggested that $\mathrm{CD} 8+\mathrm{T}$ cells populate the developing skin lesion first, while also being the predominant $\mathrm{T}$ cell in the synovial fluid of PsA patients, suggesting these cells may be primary drivers of this immune response. This notion was supported by assessing the use of lymphocyte-specific therapy for psoriatic patients who led to reduction of CD8+T cells in the epidermis, and this correlated with clinical improvement. The observation that PsA is an HLA class I-associated disease and that more severe disease occurs in association with human immunodeficiency virus infection gives further significance to the role of CD8+ T cells in the pathogenesis of psoriasis and PsA [20]. Furthermore, the possible use of acyclovir for the treatment of psoriasis, though this has not been studied fully, raised questions about the role of the adaptive immune system and infection as possible precipitating or exacerbating factor for psoriasis [21]. Understanding the disease pathogenesis would have a positive impact on early identification of the disease-specific predictors of psoriatic patients suffering from early inflammatory process in their spine or joints.

\section{The concept of early psoriatic arthritis}

Window of opportunity: Early detection and treatment of chronic inflammatory joint disease has been shown in numerous reports to correlate with better long-term outcome in rheumatoid arthritis $[22,23]$. Severity of joint destruction and loss of quality of life in PsA has been shown to be similar to RA [24,25]. Therefore, many aspects in PsA may be compared with aspects in RA. Earlier studies revealed that the chronic inflammatory process begins with an undulating situation of clinical and subclinical manifestations of joint pain with or without swelling. A trigger event then sets off the clinical chronic inflammatory course. Joint destruction begins very early after this event. If the inflammatory process is not stopped, the natural disease course will occur with more or less destruction of joint structures [26]. A study that included PsA patients within 5 months of onset of symptoms identified $27 \%$ of the patients to have erosive disease at presentation to the clinic, suggesting that the disease may be aggressive at an early stage [10]. Follow up of these patients for 2 -years revealed that $47 \%$ of them patients were found to have erosive joint disease despite the fact that 
the majority had been treated with disease-modifying antirheumatic drugs (DMARD). Studies of adalimumab [27] and etanercept [28] showed changes in HAQ scores in the order of 50-60\% improvement associated with radiographic improvement. The concept of "window of opportunity" in spondyloarthritis with psoriasis came from the finding that there is a pre-radiographic stage where the patient would be suffering from inflammatory back pain/ inflammatory arthritis. This is usually followed by the classic stage of the disease where the patient might develop joint erosions and deformities. If we treat early in the disease process to the target of remission and control the inflammatory process, it is possible to prevent or slow down the destructive process not only in the joints, but also to stop syndesmophyte formation [29]. A recent study that used musculoskeletal US for early diagnosis of PsA and monitoring response to therapy showed that early diagnosis and treatment of PsA could prevent progression of joint damage and improve functional disability [30].

\section{Fatty lesions in axial SpA "The missing link"}

MRI scans of the axial spine early in SpA showed significant changes in the form of fatty lesions in both the sacroiliac joints and the spine which seem to be the first sign of chronic bone damage [31]. A recent study done by Song et al. [32], linked the occurrence of fatty lesions and inflammation to the development of new bone formation. It was postulated that fatty lesions at the vertebral corners (Figure 2) are the first chronic changes after inflammation and that they are necessary for the later development of syndesmophytes. Thus, if fatty lesions could be avoided early (in the first 6-12 months) this might be an indicator that new bone formation can also be avoided. This proposed link was further supported by the findings of another study which reported that radiographic syndesmophytes after 2 years were present in $12 \%$ of the vertebral edges that showed fatty lesions at baseline but only in $2 \%$ of patients without fatty lesions at baseline [32]. The pivotal role of early treatment of SpA patients was documented in the study done by Song et al. [32] using TNF blocker treatment for patients with early axial SpA. Results showed that early treatment prevented the occurrence of early chronic changes, such as fatty lesions, in about $80 \%$ of inflammatory lesions which were successfully cleared by etanercept treatment. Though molecular basis for the link between inflammation and new bone formation in SpA is still not clear, it has recently been shown that low serum levels of the molecules sclerostin [33] and Dickkopf 1 (DKK1) [34] which are both important for osteoclast activation and osteoblast inhibition, are associated with the formation of new syndesmophytes in SpA patients.

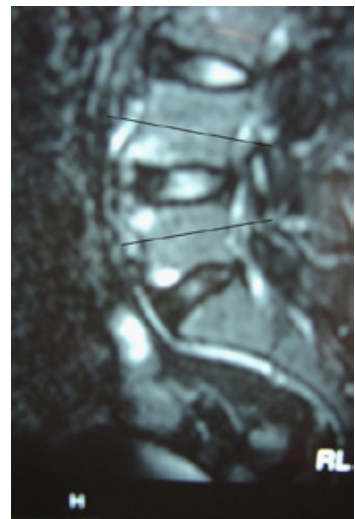

Figure 2: Sagittal T1 weighted post-contrast fat suppressed image of the spine showing quadrant MR lesions with increased contrast uptake after intravenous gadolinium at the anterior corners of $L 4 / 5$ "MRI corner sign".

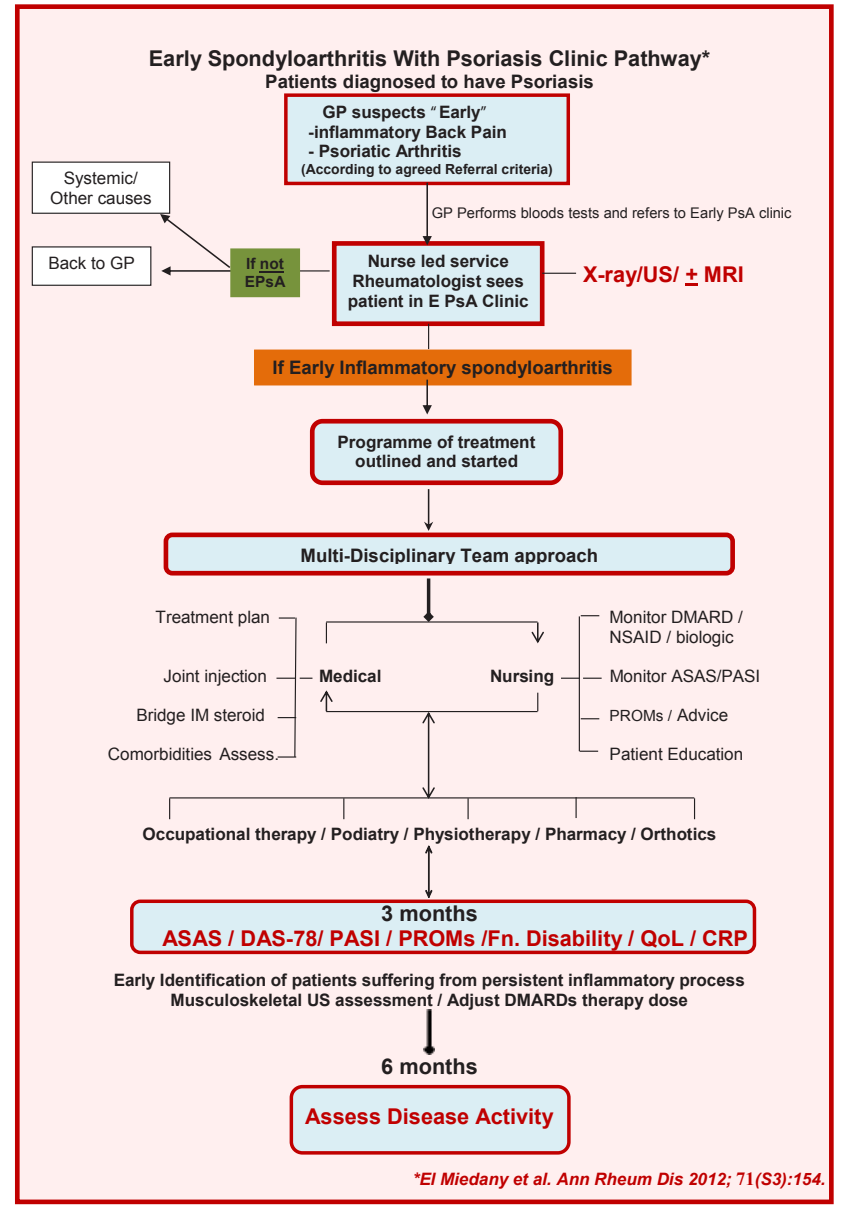

Figure 3: Suggested pathway for early psoriatic arthritis clinic [27].

Thus, taking all imaging and molecular data in SpA together, levels of inflammation are necessary for the development of chronic lesions such as fatty lesions in subchondral bone marrow and the development of syndesmophytes. These data reported reveals how fatty lesions in axial SpA might provide a missing link between the inflammatory process and syndesmophyte formation and the value of starting treatment for SpA in early stages.

\section{Early spondyloarthritis with psoriasis clinic}

One of the most intriguing features of PsA is that it usually arises in patients with pre-existing psoriasis. Though, in about $70 \%$ of PsA cases the onset of psoriasis precedes that of arthritis, the arthritis has been reported to precede the skin disease in about $15 \%$ of cases, and the two occur simultaneously in the other 15\% [3]. Radiographic damage was reported within 2 years of disease onset in almost half of patients with PsA, and the disease follows a chronic, progressive course in most patients $[9,10]$. Thus, investigators and clinicians have a unique opportunity to screen a defined population with a distinctive cutaneous phenotype in order to identify patients with PsA early in the disease course.

In the standard clinical practice, psoriatic patients with a dominant skin manifestation primarily consult their general practitioners and in severe cases the dermatologists, whereas patients with a dominant peripheral or spinal manifestation primarily consult rheumatologists. Therefore, it seems rational to set a pathway to screen psoriatic patients 
for arthritic or spondylitis manifestations. In view of the fact that not all psoriatic patients would suffer from inflammatory arthritis or spondylitis, it is necessary to identify those who are suffering from persistent inflammatory arthritis/spondylitis, which might eventually lead to establishing prognostic parameters for PsA. Figure 3 shows a pathway of a suggested Early PsA Clinic. In patients with psoriasis sensitivity of the referral criteria was $89.9 \%$ and specificity $91.7 \%$ whereas in PsA sine-psoriasis patients the sensitivity of referral criteria was $74.6 \%$ whereas specificity of $83.2 \%$ [30]. Good cooperation between the dermatologist, rheumatologist as well as the general practitioner is mandatory for the success of such service.

However, there are challenges to this approach. The term 'early spondyloarthritis with psoriasis or early PsA' remains imprecisely defined, and the duration of 'early' disease can range from several months to anything less than 5 years [9,29-35]. Spondyloarthritis with psoriasis can present with a wide spectrum of clinical manifestations which may delay diagnosis. Furthermore, the absence of diseasespecific biomarkers, such as anti-cyclic citrullinated peptide antibodies or rheumatoid factor as in the case of rheumatoid arthritis, leads to reliance on clinical phenotype, which may come to medical attention at a more advanced disease stage. Also, joint inflammation could be clinically underestimated and may not be detected until damage is noted on radiographs or physical examination (Appendix 1). Patients with PsA are reported to have less joint tenderness than patients with rheumatoid arthritis [36]. Moreover, axial inflammation may be clinically silent [37-39]. This paved the way for the imaging modalities to play a role in the assessment and management of early as well as established spondyloarthritis with psoriasis.

\section{The Imaging Arm}

Imaging of the sacroiliac joints and the spine has gained an important role in the diagnosis, classification and monitoring of patients with SpA. Sacroiliitis on conventional radiography was given an outstanding role in the development of classification criteria in modified New York criteria in 1984 [40]. Usually bilateral grade $\geq 2$ or unilateral grade $\geq 3$ sacroiliitis are considered critical for the diagnosis of spondyloarthritis [41].

However, radiographic sacroiliitis which reflects structural changes usually appear later in the disease process at least in a subset of patients [42]. Thus, it has low specificity especially for patients at the early stages of the disease. The recently introduced concept of Early spondyloarthritis raised the need to more sensitive radiologic tools to enable the treating doctor identify the disease activity in the preradiographic stage.

Magnetic resonance imaging (MRI) can visualize active inflammation at sacroiliac joints and spine in early pre-radiological axial disease, regardless of disease stage. The modified New York criteria, ESSG criteria and the Amor criteria for spondyloarthritis do not contain MRI as an imaging tool [42]. The most recent ASAS classification criteria for axial spondyloarthritis were developed for early and established cases and include the MRI technique (active inflammation) as an important tool for early diagnosis. ASAS classification criteria for axial SpA have imaging and clinical arms. The imaging arm includes either sacroiliitis on conventional radiography or sacroiliitis on MRI (Figures 4a-4c), which is highly important for recognition of pre-radiographic changes in early SpA [43].

However, this important diagnostic growing role of MRI raises an important question, will MRI-tis will be the magic wand to diagnose

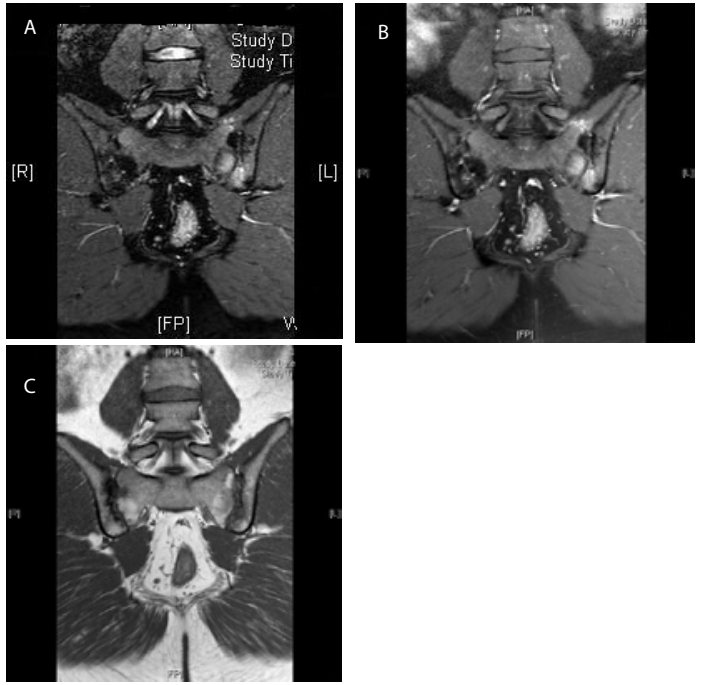

Figure 4(a,b,c): Oblique coronal T1 W, STIR and post-contrast fat suppressed $\mathrm{T} 1 \mathrm{~W}$ images of both sacroiliac joints showing bilateral sacroiliitis more on the left side with significant contrast uptake after intravenous Gadolinium. A linear region of similar signal changes and contrast is also noted involving the superior bone margin of the left sacral ala and the adjacent iliacus muscle.

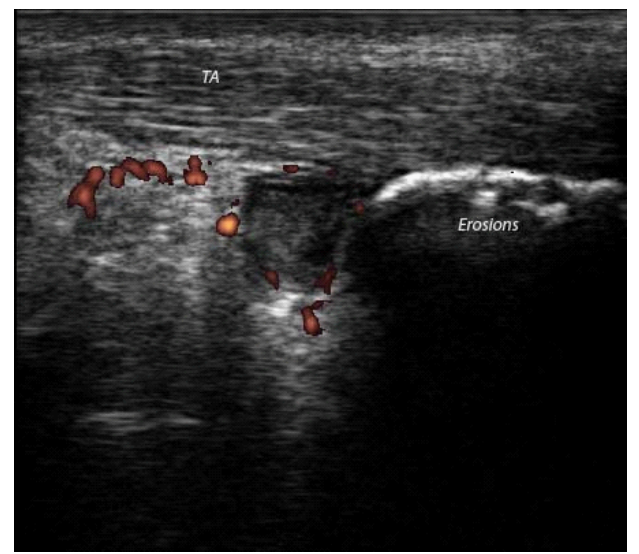

Figure 5: Tendo Achilles enthesitis in psoriatic arthritis patients detected by ultrasound (US) examination Power Doppler mode showing abnormal vascularization associated with marked swelling and decreased echogenicity of the enthesis at the cortical junction, as well as erosions of the calcaneus. Tendon thickness at the level of the enthesis is $7.3 \mathrm{~mm}$ associated to a retrocalcaneal bursa with enhanced vascularity.

spondyloarthritis? Though MRI-detected changes associated with axial SpA have been attributed a major role in the ASAS criteria, this is significant only in the presence of clinical symptoms suggestive for $\mathrm{SpA}$. According to the ASAS classification criteria, clinical examination remains the first step of the diagnostic process in patients with suspected SpA. The optimal indication to order MRI is the presentation of patients with potential non-radiographic axial SpA [44] Therefore, MRI can confirm a diagnosis of non-radiographic SpA, suspected on clinical grounds, but will never be able to capture all phenotypes of the multi-faceted spectrum of SpA [45].

\section{Ultrasonography}

Considering the common pathogenesis between the psoriatic plaque and synovial membrane and the finding that the common denominator in psoriasis as well as PsA may be related to aberrant 

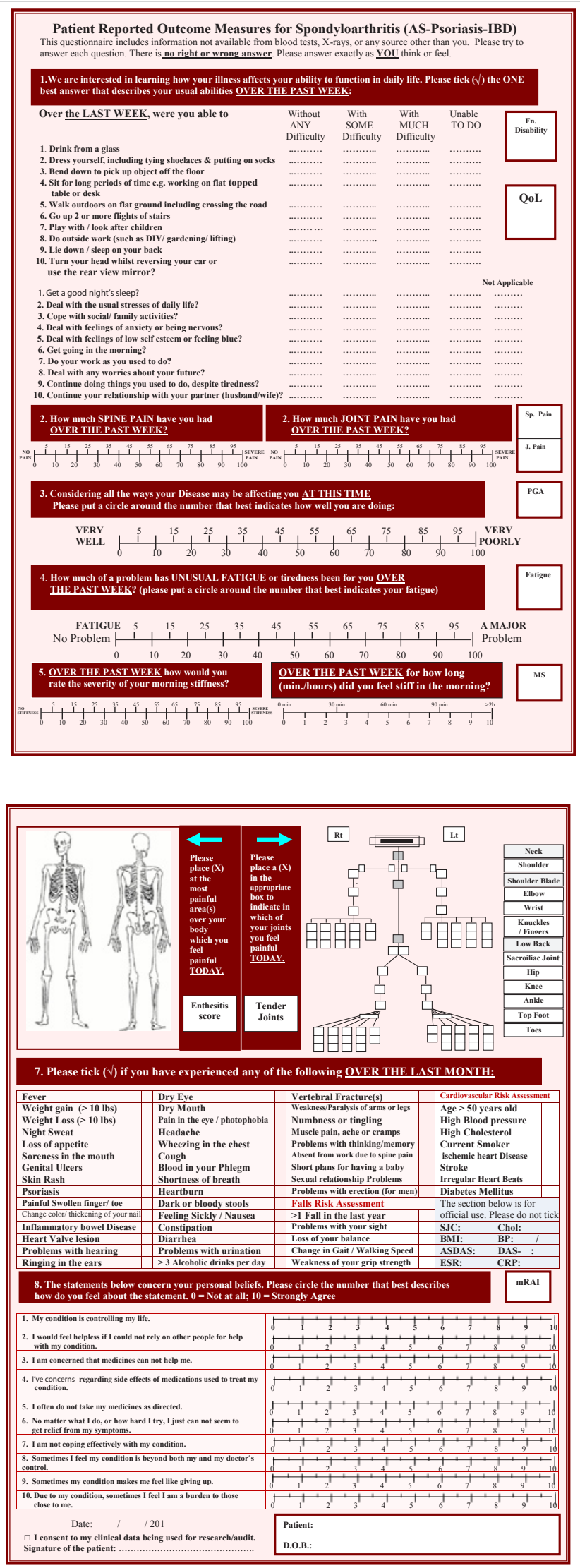

Figure 6: Patient reported outcome measures questionnaire for spondyloarthritis patients [59]. responses to stress at the enthesis/skin, musculoskeletal US, having the advantage of dynamic assessment of inflamed tissues, booked its place in the assessment and management of PsA. Recently, the Group for Research and Assessment of Psoriasis and Psoriatic Arthritis (GRAPPA) underlined the value of US imaging findings in PsA, from both dermatologic and rheumatic perspectives [45]. In several recent studies, musculoskeletal US provided a widespread and more complete assessment of morphostructural changes and disease activity at different locations in patients with PsA [46]. In this way, there is a consistent body of evidence supporting both the role of US and its higher sensitivity to support clinical examination in the assessment of PsA in standard clinical practice $[47,48]$. The potential use of US in the assessment of skin and musculoskeletal involvement in PsA patients include: joints, tendons, enthesitis (Figure 5), psoriatic skin lesion and nails [49]. Moreover, US were found valuable in the assessment of disease activity and response to therapy in PsA patients. US were found sensitive to inflammatory and destructive changes than plain radiographs and clinical examination. Furthermore, US demonstrated a good inter-observer agreement for bone changes (median 96\% absolute agreement) as well as inter-observer agreement for inflammatory changes (median 92\% absolute agreement) [50]. Other studies revealed that US can be used as an outcome measure to monitor response to therapy in inflammatory arthritis [49,51].

Taken together, MRI and US imaging modalities are expected to play an important role in spondyloarthritis with psoriasis, not only to detect subclinical joint or spine inflammation, but also to assist the clinician in the evaluation of early PsA and monitor response to therapy.

\section{Patient reported outcome measures and patient education}

Outcome measures in spondyloarthritis with psoriasis are not standardized and most of the assessment methodologies have been adapted from clinical trials in rheumatoid arthritis (RA), with few disease-specific instruments currently available [51]. The Outcome Measures in Rheumatology (OMERACT) proposed a core set of 6 domains of health to be included in randomized clinical trials and observational studies regarding PsA: joints, skin, pain, patient global assessment, physical function, and health-related quality of life [52].

In the last decade, outcome measures based on patients' opinions, i.e., patient-reported outcome measures (PROMs), have become critical outcomes in both clinical trials as well as standard clinical practice of rheumatic diseases [53-55]. PROMs, defined as any measure of a patient's health status that is elicited directly from the patient and assesses how the patient feels or functions with respect to this health condition, reflect the patient burden of disease and feeling of wellness more accurately [56]. Furthermore, PROMs should be assessed because a discrepancy has been found between patients' and physicians' opinions in several diseases [57-59]. Instruments for measuring PROMs (Figure 6) are easy to administer and some, have been proven to be reliable, valid, and sensitive to change $[60,61]$. There are several ways to explore PROMs: some are qualitative [62], whereas others are quantitative such as by assessing the frequency of different outcome measures [53,63]. Recent PROMs in SpA with psoriasis patients (Figure 7) can be stratified into: 1) Disease Activity core set domains: this include clinical outcomes related to joints, pain, skin, patient global assessment, physical function, and quality of life; 2) Non-articular domains: enthesitis, dactylitis, spine, fatigue, as well as nail disease; and 3) Comorbidity assessment: Cardiovascular risk, falls risk, osteoporosis risk, sexual dysfunction, ability to work and self-helplessness.

A recent study [64] assessed the utility of visual feedback based 


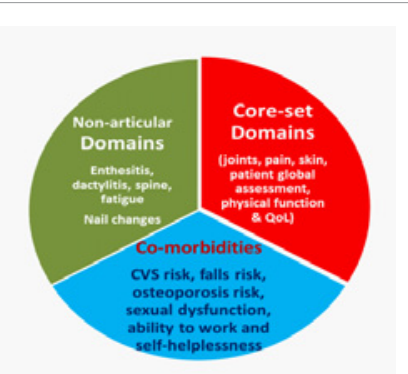

Figure 7: Domains assessed in Patient Reported Outcome measures in Psoriatic arthritis patients.

on PROMs records in patients suffering from inflammatory arthritis. Results revealed that by sharing the previous PROMs measures recorded with the patients lead to significant improvement of the patients' adherence to anti-rheumatic therapy and provided a significant greater reduction of disease activity parameters. Also stopping the DMARDs therapy because of intolerance was significantly less in the active group who were able to view their former PROMs scores. In contrast concerns about the future, inability to coup with daily life and disease stress were significantly more among the control group who did not view their former PROMs records. As expected the improvement of disease activity parameters was associated with improvement in functional disability and quality of life scores. Another recent study [65] showed that PROMs can be used to designing a tailored approach to Patient education and self-management program.

In conclusion, the wide range of disease manifestations in spondyloarthritis with psoriasis, especially in early stages of the disease, presents a challenge to the treating physician and warrants individualized treatment approach. The identification of patients early in the disease course is hampered by phenotypic heterogeneity and the absence of a diagnostic biomarker. This paved the way for imaging modalities such as MRI and US to work as biomarkers for early diagnosis of the inflammatory process, as they provide detailed assessment of soft tissues and musculoskeletal structures that might not be seen in traditional radiography. In addition, patient reported outcome measures questionnaires have been developed to help screen patients with psoriasis for the presence of musculoskeletal disease and its impact on their lives. Early PsA clinics offer a golden chance to catch this window of opportunity to prevent subsequent disability and joint/ spinal damage. These developments in our understanding of the disease and its implications led to a similar change in the therapeutic approach, which has been modified to use treatments that may benefit both the skin and joint manifestations of the disease while ensuring minimal adverse effects. Disease remission, which was once a distant goal in rheumatology, became a more realistic aim of treatment.

\section{References}

1. Brockbank J, Gladman D (2002) Diagnosis and management of psoriatic arthritis. Drugs 62: 2447-2457.

2. Wright V, Moll JM (1971) Psoriatic arthritis. Bull Rheum Dis 21: 627-32.

3. Gladman DD, Shuckett R, Russell ML, Thorne JC, Schachter RK (1987) Psoriatic arthritis (PSA)-an analysis of 220 patients. Q J Med 62: 127-141.

4. Gladman DD, Anhorn KA, Schachter RK, Mervart H (1986) HLA antigens in psoriatic arthritis. J Rheumatol 13: 586-592.

5. Gladman DD (2002) Current concepts in psoriatic arthritis. Curr Opin Rheumatol 14: $361-366$.

6. Madland TM, Apalset EM, Johannessen AE, Rossebö B, Brun JG (2005)
Prevalence, disease manifestations, and treatment of psoriatic arthritis in Western Norway. J Rheumatol 32: 1918-1922.

7. Salvarani C, Olivieri I, Cantini F, Macchioni L, Boiardi L (1998) Psoriatic arthritis. Curr Opin Rheumatol 10: 299-305.

8. Shbeeb M, Uramoto KM, Gibson LE, O'Fallon WM, Gabriel SE (2000) The epidemiology of psoriatic arthritis in Olmsted County, Minnesota, USA, 19821991. J Rheumatol 27: 1247-1250.

9. Kane D, Stafford L, Bresnihan B, FitzGerald O (2003) A prospective, clinical and radiological study of early psoriatic arthritis: an early synovitis clinic experience. Rheumatology (1460-1468) 42: 1460-1468.

10. Zachariae H, Zachariae R, Blomqvist K, Davidsson S, Molin L, et al. (2002 ) Quality of life and prevalence of arthritis reported by 5,795 members of the Nordic Psoriasis Associations: Data from the Nordic Quality of Life Study. Acta Derm Venereol 82: 108-113.

11. Mease P ( 2006) Psoriatic arthritis update. Bull NYU Hosp Jt Dis 64: 25-31.

12. Kavanaugh AF, Ritchlin CT (2006) Systematic review of treatments for psoriatic arthritis: an evidence based approach and basis for treatment guidelines. $J$ Rheumatol 33: 1417-1421.

13. Dougados M (2012) Spondyloarthritis: what is new in 2012? Ann Rheum Dis 71: 45.

14. Kruithof E, Baeten D, De Rycke L, Vandooren B, Foell D D, et al. (2005) Synovial histopathology of psoriatic arthritis, both oligo- and polyarticular, resembles spondyloarthropathy more than it does rheumatoid arthritis. Arthritis Res Ther 7: R569-580.

15. Nograles KE, Brasington RD, Bowcock AM (2009) New insights into the pathogenesis and genetics of psoriatic arthritis. Nat Clin Pract Rheumatol 5: 83-91.

16. McGonagle D, Lories RJ, Tan AL, Benjamin M (2007) The concept of a "synovioentheseal complex" and its implications for understanding joint inflammation and damage in psoriatic arthritis and beyond. Arthritis Rheum 56: 2482-2491.

17. Benjamin M, McGonagle D (2007) Histopathologic changes at "synovioentheseal complexes" suggesting a novel mechanism for synovitis in osteoarthritis and spondylarthritis. Arthritis Rheum 56: 3601-3609.

18. McGonagle D, Tan AL, Benjamin M (2008) The biomechanical link between skin and joint disease in psoriasis and psoriatic arthritis: what every dermatologist needs to know. Ann Rheum Dis 67: 1-4.

19. Veale DJ, Ritchlin C, FitzGerald O (2005) Immunopathology of psoriasis and psoriatic arthritis. Ann Rheum Dis 64: ii26-ii29.

20. Veale DJ (2011) New therapies and new goals for psoriatic arthritis. Arthritis Rheum 63: 874-876.

21. Ito T, Furukawa $F(2000)$ Psoriasis guttate acuta triggered by varicella zoster virus infection. Eur J Dermatol 10: 226-227.

22. Verstappen SM, Watson KD, Lunt M, McGrother K, Symmons DP, et al. (2010) Working status in patients with rheumatoid arthritis, ankylosing spondylitis and psoriatic arthritis: results from the British Society for Rheumatology Biologics Register. Rheumatology (Oxford) 49: 1570-1577.

23. van der Bijl AE, Goekoop-Ruiterman YP, de Vries-Bouwstra JK, Ten Wolde $\mathrm{S}$, Han $\mathrm{KH}$, et al. (2007) Infliximab and methotrexate as induction therapy in patients with early rheumatoid arthritis. Arthritis Rheum 56: 2129-2134.

24. Rahman P, Nguyen E, Cheung C, Schentag CT, Gladman DD (2001) Comparison of radiological severity in psoriatic arthritis and rheumatoid arthritis. J Rheumatol 28: 1041-1044.

25. Husted JA, Gladman DD, Farewell VT, Cook RJ (2001) Health-related quality of life of patients with psoriatic arthritis: a comparison with patients with rheumatoid arthritis. Arthritis Rheum 45: 151-158.

26. Wilson FC, Icen M, Crowson CS, McEvoy MT, Gabriel SE, et al. (2009) Incidence and Clinical Predictors of Psoriatic Arthritis in Patients With Psoriasis: A Population-Based Study. Arthritis Rheum 61: 233-239.

27. Mease PJ, Gladman DD, Ritchlin CT, Ruderman EM, Steinfeld SD, et al . (2005) Adalimumab for the treatment of patients with moderately to severely active psoriatic arthritis: results of a double-blind, randomized, placebo-controlled trial. Arthritis Rheum 52: 3279-3289. 
28. Mease PJ, Kivitz AJ, Burch FX, Siegel EL, Cohen SB, et al. (2004) Etanercept treatment of psoriatic arthritis: safety, efficacy, and effect on disease progression. Arthritis Rheum 50: 2264-2272.

29. Sieper J, Rudwaleit M (2005) How early should ankylosing spondylitis be treated with tumour necrosis factor blockers? Ann Rheum Dis 64: iv61-iv64.

30. El Miedany Y, El Gaafary M, Youssef S, Palmer D (2012) The role of musculoskeletal US as an outcome measure in the diagnosis and management of early psoriatic arthritis. Ann Rheum Dis 71: 184.

31. Harrison BJ, Silman AJ, Barrett EM, Scott DG, Symmons DP (1997) Presence of psoriasis does not influence the presentation or short-term outcome of patients with early inflammatory polyarthritis. J Rheumatol 24 1744-1749.

32. Song IH, Hermann KG, Haibel H, Althoff CE, Poddubnyy D, et al. (2011) Relationship between active inflammatory lesions in the spine and sacroiliac joints and new development of chronic lesions on whole-body MRI in early axial spondyloarthritis: results of the ESTHER trial at week 48. Ann Rheum Dis 70: $1257-1263$

33. Chiowchanwisawakit P, Lambert RG, Clare T (2008) Post-inflammatory focal fat lesions in the spine of patients with ankylosing spondylitis predict development of new syndesmophytes. Arthritis Rheum 58: 356.

34. Appel H, Ruiz-Heiland G, Listing J, Zwerina J, Herrmann M, et al. (2009) Altered skeletal expression of sclerostin and its link to radiographic progression in ankylosing spondylitis. Arthritis Rheum 60: 3257-3262 .

35. Sieper J, Appel H, Rudwaleit M (2010) Inverse correlation between serum levelsof dickkopf 1 (DKK 1), and new bone formation in ankylosing spondylitis patients. Ann Rheum Dis 69: 442.

36. Punzi L, Pianon M, Bertazzolo N, Fagiolo U, Rizzi E, et al. (1998) Clinical, laboratory and immunogenetic aspects of post-traumatic psoriatic arthritis: a study of 25 patients. Clin Exp Rheumatol 16: 277-281.

37. Harrison BJ, Hutchinson CE, Adams J, Bruce IN, Herrick AL (2002) Assessing periarticular bone mineral density in patients with early psoriatic arthritis or rheumatoid arthritis. Ann Rheum Dis 61: 1007-1011.

38. Buskila D, Langevitz P, Gladman DD, Urowitz S, Smythe HA (1992) Patients with rheumatoid arthritis are more tender than those with psoriatic arthritis. J Rheumatol 19: 1115-1119.

39. Queiro R, Belzunegui J, Gonzalez C, De DJ, Sarasqueta C, et al. (2002) Clinically asymptomatic axial disease in psoriatic spondyloarthropathy. A retrospective study. Clin Rheumatol 21: 10-13.

40. van der Linden S, Valkenburg HA, Cats A (1984) Evaluation of diagnostic criteria for ankylosing spondylitis. A proposal for modification of the New York criteria. Arthritis Rheum 27: 361-368.

41. Rudwaleit M, Haibel H, Baraliakos X, Listing J, Märker-Hermann E, et al. (2009) The early disease stage in axial spondylarthritis: results from the German Spondyloarthritis Inception Cohort. Arthritis Rheum 60: 717-727.

42. De Rycke L, Maas M, Tak PP, Baeten D (2010) 'MRI-tis' in the early diagnosis of axial SpA: issues and limitations. Nat Rev Rheumatol 6: 666-669.

43. Rudwaleit M, van der Heijde D, Landewé R, Listing J, Akkoc N, et al (2009) The development of Assessment of SpondyloArthritis international Society classification criteria for axial spondyloarthritis (part II): validation and final selection. Ann Rheum Dis 68: 777-783.

44. Heuft-Dorenbosch L, Landewé R, Weijers R, Wanders A, Houben $\mathrm{H}$, et al (2006) Combining information obtained from magnetic resonance imaging and conventional radiographs to detect sacroiliitis in patients with recent onset inflammatory back pain. Ann. Rheum Dis 65: 804-808.

45. van der Heijde D, Rudwaleit M, Landewé RB, Sieper J (2010) Justification for including MRI as a tool in the diagnosis of axial SpA. Nat Rev Rheumatol 6 : 670-672.

46. Coates LC, Anderson RR, Fitzgerald O, Gottlieb AB, Kelly SG, et al. (2008) Clues to the pathogenesis of psoriasis and psoriatic arthritis from imaging: a literature review. J Rheumatol 35: 1438-1442.

47. Gutierrez M, Filippucci E, De Angelis R, Filosa G, Kane D, et al (2010) A sonographic spectrum of psoriatic arthritis: "the five targets". Clin Rheumatol 29: 133-142.

48. Weiner SM, Jurenz S, Uhl M, Lange-Nolde A, Warnatz K, et al. (2008)
Ultrasonography in the assessment of peripheral joint involvement in psoriatic arthritis: a comparison with radiography, MRI and scintigraphy. Clin Rheumatol 27: 983-989.

49. Wiell C, Szkudlarek M, Hasselquist M, Møller JM, Vestergaard A, et al. (2007) Ultrasonography, magnetic resonance imaging, radiography, and clinical assessment of inflammatory and destructive changes in fingers and toes of patients with psoriatic arthritis. Arthritis Res Ther 9: R119 .

50. El Miedany Y (2012) Musculoskeletal US: taking the management of psoriatic arthritis to a new horizon. Current Rheum Rev 8: 12-19.

51. D'Agostino MA, Conaghan PG, Naredo E, Aegerter P, lagnocco A, et al. (2009) The OMERACT ultrasound task force -- advances and priorities. J Rheumatol 36: $1829-1832$.

52. Gladman DD, Helliwell P, Mease PJ, Nash P, Ritchlin C, et al. (2004) Assessment of patients with psoriatic arthritis: a review of currently available measures. Arthritis Rheum 50: 24-35.

53. Gladman DD, Mease PJ, Strand V, Healy P, Helliwell PS, et al. (2007) Consensus on a core set of domains for psoriatic arthritis. J Rheumatol 34: 1167-1170.

54. Scoggins JF, Patrick DL (2009) The use of patient-reported outcomes instruments in registered clinical trials: evidence from ClinicalTrials.gov. Contemp Clin Trials 30: 289-292.

55. Kalyoncu U, Dougados M, Daures JP, Gossec L (2009) Reporting of patientreported outcomes in recent trials in rheumatoid arthritis: a systematic literature review. Ann Rheum Dis 68: 183-190.

56. Kirwan JR, Minnock P, Adebajo A, Bresnihan B, Choy E, et al. (2007) Patient perspective: fatigue as a recommended patient centered outcome measure in rheumatoid arthritis. J Rheumatol 34: 1174-1177.

57. Acquadro C, Berzon R, Dubois D, Leidy NK, Marquis P, et al. (2003) Incorporating the patient's perspective into drug development and communication: an ad hoc task force report of the Patient-Reported Outcomes (PRO) Harmonization Group meeting at the Food and Drug Administration, February 16, 2001. Value Health 6: 522-531.

58. Kwoh CK, O'Connor GT, Regan-Smith MG, Olmstead EM, Brown LA, et al. (1992) Concordance between clinician and patient assessment of physical and mental health status. J Rheumatol 19: 1031-1037.

59. Neville C, Clarke AE, Joseph L, Belisle P, Ferland D, et al. (2000) Learning from discordance in patient and physician global assessment of systemic lupus erythematosus disease activity. J Rheumatol 27: 675-679.

60. Hidding A, van Santen M, De Klerk E, Gielen X, Boers M, et al $\square$ (1994) Comparison between self-report measures and clinical observations of functional disability in ankylosing spondylitis, rheumatoid arthritis and fibromyalgia. J Rheumatol 21: 818-823.

61. Bruce B, Fries JF (2003) The Stanford Health Assessment Questionnaire (HAQ): a review of its history, issues, progress, and documentation. J Rheumatol 30: 167-178.

62. El Miedany Y, Palmer D, Youssef S, El Gaafary M (2010) Towards a Multidimensional Patient Reported Outcome Measures Assessment: Development and Validation of a questionnaire for patients with Ankylosing Spondylitis /Spondyloarthritis. Joint Bone Spine 77: 575-581.

63. Stamm TA, Nell V, Mathis M, Coenen M, Aletaha D, et al. (2007) Concepts important to patients with psoriatic arthritis are not adequately covered by standard measures of functioning. Arthritis Rheum 57: 487-494

64. El Miedany Y, El Gaafary M, Palmer D (2012) Assessment of the utility of visua feedback in the treatment of early rheumatoid arthritis patients: a pilot study. Rheumatol Int 32: 3061-3068.

65. Palmer D, El Miedany Y (2012) PROMs: a novel approach to arthritis selfmanagement. Br J Nurs 21: 601-602, 605-607. 